\title{
An LDLR missense variant poses high risk of familial hypercholesterolemia in $30 \%$ of Greenlanders and offers potential for early cardiovascular disease intervention
}

Emil Jørsboe ${ }^{1,2,13}$; Mette K. Andersen²,13; Line Skotte ${ }^{8}$; Frederik Filip Stæger ${ }^{1}$; Nils J. Færgeman ${ }^{3}$; Kristian Hanghøj ${ }^{1}$; Cindy G. Santander ${ }^{1}$; Ninna Karsbæk Senftleber ${ }^{1,4}$; Lars J. Diaz ${ }^{4}$; Maria Overvad ${ }^{4}$; Ryan K. Waples ${ }^{1}$; Frank Geller ${ }^{8}$; Peter Bjerregaard ${ }^{5}$; Mads Melbye ${ }^{9,10,11,12}$; Christina V. L. Larsen ${ }^{5,6}$; Bjarke Feenstra $^{8}$; Anders Koch ${ }^{6,8}$; Marit E. Jørgensen ${ }^{4,5,6,14}$; Niels Grarup ${ }^{2,14}$; Ida Moltke ${ }^{1,14}$; Anders Albrechtsen ${ }^{1,14}$; Torben Hansen ${ }^{2,7,14}$.

${ }^{1}$ Bioinformatics Centre, Department of Biology, University of Copenhagen, Copenhagen, Denmark. ${ }^{2}$ Novo Nordisk Foundation Center for Basic Metabolic Research, Faculty of Health and Medical Sciences, University of Copenhagen, Copenhagen, Denmark. ${ }^{3}$ Villum Center for Bioanalytical Sciences, Department of Biochemistry and Molecular Biology, University of Southern Denmark. ${ }^{4}$ Steno Diabetes Center Copenhagen, Gentofte, Denmark. ${ }^{5}$ National Institute of Public Health, University of Southern Denmark, Copenhagen, Denmark. ${ }^{6}$ Greenland Centre for Health Research, University of Greenland, Nuuk, Greenland. ${ }^{7}$ Faculty of Health Sciences, University of Southern Denmark, Odense, Denmark. ${ }^{8}$ Department of Epidemiology Research, Statens Serum Institut, Copenhagen, Denmark. ${ }^{9}$ Department of Clinical Medicine, University of Copenhagen, Copenhagen, Denmark. ${ }^{10}$ Department of Medicine, Stanford University School of Medicine, Stanford, California, USA. ${ }^{11}$ K.G.Jebsen Center for Genetic Epidemiology, Norwegian University of Science and Technology (NTNU), Norway. ${ }^{12}$ Center for Fertility and Health, Norwegian Institute of Public Health, Norway.

\footnotetext{
${ }^{13}$ Emil Jørsboe and Mette K Andersen contributed equally to this work.

14 joint senior and corresponding authors:niels.grarup@sund.ku.dk (+45 353371 26); maej@peqqik.gl; ida@binf.ku.dk (+45 617004 86); torben.hansen@sund.ku.dk (+45 353371 29); albrecht@ binf.ku.dk (+45 353302 46)
}

Word count, abstract: 249; main text:3851; tables: 1; figures: 4 .

\begin{abstract}
Background:

NOTE: This preprint reports new research that has not been certified by peer review and should not be used to guide clinical practice.
\end{abstract}


medRxiv preprint doi: https://doi.org/10.1101/2022.01.12.22269132; this version posted January $12,2022$. The copyright holder for this preprint (which was not certified by peer review) is the author/funder, who has granted medRxiv a license to display the preprint in It is made available under a CC-BY-NC-ND 4.0 International license .

The common Arctic specific $L D L R$ p.G137S variant was recently shown to be associated with elevated lipid levels. Motivated by this we aimed to investigate the effect of p.G137S on metabolic health, and cardiovascular disease risk among Greenlanders to quantify its impact on the population.

\section{Methods:}

In a population based Greenlandic cohort $(\mathrm{n}=5063)$, we tested for associations between the p.G137S variant and metabolic health traits as well as cardiovascular disease risk based on registry data.

Additionally, we explored the variant's impact on plasma NMR measured lipoprotein concentration and composition in another Greenlandic cohort $(n=1629)$.

\section{Results:}

$29.5 \%$ of the individuals in the cohort carried at least one copy of the p.G137S risk allele.

Furthermore, $25.4 \%$ of the heterozygous and $54.7 \%$ of the homozygous carriers had high levels $(>4.9$ $\mathrm{mmol} / \mathrm{L}$ ) of LDL cholesterol, which is above the diagnostic level for familial hypercholesterolemia (FH). Moreover, p.G137S was associated with an overall atherosclerotic lipid profile, and increased risk of ischaemic heart disease (HR (95\% CI), 1.51 (1.18-1.92), $\mathrm{P}=0.00096)$, peripheral artery disease (1.69 (1.01-2.82), $\mathrm{P}=0.046)$, and coronary operations (1.78 (1.21-2.62), $\mathrm{P}=0.0035)$.

\section{Conclusions:}

Due to its high frequency and large effect sizes, p.G137S has a marked population-level impact, increasing the risk of FH and cardiovascular disease for up to $30 \%$ of the Greenlandic population. Thus, p.G137S is a potential marker for early intervention in Arctic populations.

Word count, abstract: 249

Keywords: LDL cholesterol, ischemic heart disease, genetics, population medicine, cardiovascular disease, precision medicine 
medRxiv preprint doi: https://doi.org/10.1101/2022.01.12.22269132; this version posted January $12,2022$. The copyright holder for this preprint (which was not certified by peer review) is the author/funder, who has granted medRxiv a license to display the preprint in

It is made available under a CC-BY-NC-ND 4.0 International license .

\section{Introduction}

Cardiovascular disease (CVD) is the number one cause of death in many populations worldwide ${ }^{1}$. Also among Greenlanders, the CVD burden is high, and the CVD prevalence is likely to increase in the future, due to increasing life expectancy and changing lifestyle ${ }^{2,3}$. Therefore, additional focus on prevention and treatment of CVD is essential, also in the Greenlandic population.

CVD is tightly linked to alterations in the lipid homeostasis, including elevated levels of LDL cholesterol ${ }^{4-7}$. Alterations in the lipid homeostasis is associated with lifestyle factors such as unhealthy diet, physical inactivity, smoking, and alcohol intake, as well as genetic predisposition. The genetic predisposition can be monogenic, where a single variant has a large effect on lipid levels causing familial hypercholesterolemia $(\mathrm{FH})^{8}$, or polygenic where a large number of common variants each contribute with a small increase in the risk of dyslipidemia. The monogenic forms of dyslipidemia are associated with increased risk of CVD, especially ischemic heart disease ${ }^{9}$. And on average, individuals with FH die 19 years earlier than the general population from a CVD event ${ }^{10,11}$. Importantly, monogenic FH mutations seem to impose a two-fold higher risk of CVD, compared to higher LDL cholesterol caused by polygenic variants, likely due to the fact that monogenic variants manifest earlier in life than polygenic variants, leading to a greater cumulative LDL cholesterol exposure ${ }^{12,13}$. Early treatment with cholesterol-lowering drugs has been shown to improve health outcomes for FH patients, and current guidelines recommend cholesterol-lowering treatment beginning from the age of 8 to 10 years ${ }^{9,14,15}$. Hence, it is of great importance to identify and treat individuals carrying FH causing mutations early in life to reduce morbidity and mortality. The most common cause of FH is mutations in the gene ( $L D L R)$ encoding the LDL receptor (LDLR). This cell surface receptor mediates the uptake of LDL-cholesterol particles from the blood, primarily into the liver. The hepatic LDL uptake suppresses de novo synthesis of cholesterol, further reducing the concentration of circulating cholesterol ${ }^{16}$.

In Arctic populations, a common LDLR missense variant (p.G137S; rs730882082) has been identified. This variant is located in exon 4, which encodes the ligand binding domain of the receptor, and has been predicted to be deleterious ${ }^{17}$, and to reduce LDLR ligand binding by around $60 \%{ }^{18}$. The 
medRxiv preprint doi: https://doi.org/10.1101/2022.01.12.22269132; this version posted January $12,2022$. The copyright holder for this preprint (which was not certified by peer review) is the author/funder, who has granted medRxiv a license to display the preprint in

It is made available under a CC-BY-NC-ND 4.0 International license

p.G137S variant has been shown to be associated with markedly elevated levels of LDL cholesterol, total cholesterol, and apolipoprotein $\mathrm{B}^{18}$, yet it is not known if the variant is associated with increased risk of CVD. Motivated by this, we aimed to investigate the influence of the common Arctic specific LDLR p.G137S missense variant on the metabolic and cardiovascular health in Greenlanders.

\section{Methods}

\section{Study Cohorts}

The cohort used in all analyses, except for the NMR analysis, is comprised of Greenlanders living in Greenland from The Population Study in Greenland $1999(B 99 ; n=1401)$ and The Inuit Health in Transition Study (IHIT; $\mathrm{n}=3115)$, as well as Greenlanders living in Denmark (BBH; $\mathrm{n}=547)$, all collected as a part of general population health surveys of the Greenlandic population, which took place in 1999-2001 and 2005-2010 ${ }^{19,20}$. Altogether, 295 individuals participated in both B99 and IHIT, and were treated as a separate survey when adjusting for survey in the statistical analyses. For the NMR analysis, we used data from a separate Greenlandic cohort collected in 2013 as part of a population-based sample $(\mathrm{n}=1629)$, as previously described ${ }^{21}$.

\section{Genetic data}

The LDLR p.G137S variant (rs730882082) was genotyped using the KASP Genotyping Assay (LGC Genomics). The genotyping call rate was $99.42 \%$, and 0 mismatches were observed in 361 samples genotyped in duplicate. We used previously published genome-wide genotype data from the same individuals to obtain estimates of a genetic similarity matrix needed in the association analyses. This genome-wide genotype data was generated using the Illumina MetaboChip (Illumina, San Diego, CA, USA, ${ }^{22}$ ) and consisted of data from 4674 of the Greenlandic participants (IHIT, 2791; B99, 1336; $\mathrm{BBH}, 547)$ and 115,182 SNPs after quality control. Both the genotyping procedure and quality control for the SNP chip dataset have previously been described in detail ${ }^{23}$. For the $L D L R$ p.G137S variant genotyping and the MetaboChip data there was an overlap of 4653 individuals. This is the data set we based our analyses of metabolic phenotypes on. 
medRxiv preprint doi: https://doi.org/10.1101/2022.01.12.22269132; this version posted January $12,2022$. The copyright holder for this preprint (which was not certified by peer review) is the author/funder, who has granted medRxiv a license to display the preprint in

It is made available under a CC-BY-NC-ND 4.0 International license .

For the cohort with NMR data, the genome-wide genotype data was generated using the Illumina OmniExpressExome SNP chip (Illumina, San Diego, CA, USA). After quality control this cohort comprised 1570 participants and genotypes of 643,734 SNPs ${ }^{21}$.

\section{Analysis of metabolic phenotypes}

Since the Greenlandic study cohorts contain admixed individuals with both Inuit and European ancestry, and numerous close relatives ${ }^{24}$, we used a linear mixed model to perform the association analyses. This type of model takes admixture and relatedness into account by including them as a random effect. Specifically, we used the linear mixed model software tool GEMMA (v0.95alpha) ${ }^{25}$ for quantitative traits and GMMAT ${ }^{26}$ for binary traits. To perform the analyses we first estimated a genetic similarity matrix for all participants with both genotype and phenotype data available from quality controlled genome-wide SNP chip data. The estimation was performed by applying GEMMA to standardised genotypes from the SNPs with MAF of at least 5\% and missingness of maximum $1 \%$. Association tests were then performed using a score test in GEMMA and a Wald test in GMMAT and effect sizes and standard errors were estimated using a restricted maximum likelihood (REML) approach. For the quantitative traits we used a rank-based inverse normal transformation prior to analysis and we reported effect size estimates in standard deviations $\beta_{S D}$. This transformation was done independently for men and women. To get effect size estimates in the measured units, we also performed analyses of non-transformed trait values. In all tests we assumed an additive model and included sex, age and survey (IHIT, B99, BBH) as covariates.

\section{Analysis of CVD data}

We used the R-package survival ${ }^{27}$ for Cox regression analyses, adjusting for sex, age, survey, and the top 10 genetic principal components (PCs), based on the genome-wide genotype data. The top $10 \mathrm{PCs}$ were included to correct for population structure. Follow-up time was calculated as years lived from birth to an event, death of other causes, emigration, or end of follow-up (December 31th 2016). A second analysis was done in the same way, but with follow-up time calculated as years from inclusion in study, and thereby excluding individuals with a CVD event of that type before the study initiation. 
medRxiv preprint doi: https://doi.org/10.1101/2022.01.12.22269132; this version posted January $12,2022$. The copyright holder for this preprint (which was not certified by peer review) is the author/funder, who has granted medRxiv a license to display the preprint in It is made available under a CC-BY-NC-ND 4.0 International license .

Also a logistic regression using GMMAT, in the same way as previously described, was done for each type of CVD event defining cases as anyone with a CVD event of that type, to estimate the crosssectional CVD risk.

More detailed information on the methods used is available in the supplementary material.

\section{Results}

In the Greenlandic population, which has both Inuit and European ancestry, we estimated that the LDLR missense variant (p.G137S) had a minor allele frequency (MAF) of 15.8\%, and that the minor allele was carried by $29.5 \%$ of the population. Within the Inuit ancestry component of the population we estimated a MAF of $22.7 \%$ and of $0.0 \%$ in the European ancestry component. In line with this we estimated the variant to be extremely rare $(\mathrm{MAF}<0.005 \%)$ in non-Arctic populations (Table $\mathrm{S} 1)$. Even though p.G137S is a missense variant it might still act as an expression quantitative trait locus however, we observed no association between p.G137S genotype and expression of LDLR RNA in blood $(\mathrm{P}=0.22$; Figure $\mathrm{S} 1)$.

\section{Metabolic phenotypes}

We first assessed how the p.G137S variant affected a range of metabolic traits in a cohort of 4653 Greenlanders. We confirmed a strong association between the A-allele of the p.G137S variant and elevated concentrations of circulating LDL cholesterol $\left(\beta, 0.75 \mathrm{mmol} / \mathrm{L}, \mathrm{P}=5.5 \cdot 10^{-87}\right.$, Table 1 and Figure 1A). The effect was additive, and similar across age groups (Figure S2), as well as degree of Inuit ancestry (Figure S3). As shown in Figure 1B, we observed that 8.0\%, 25.4\%, and 54.7\% of non-, heterozygous, and homozygous p.G137S A-allele carriers, respectively, had high LDL cholesterol levels $(>4.9 \mathrm{mmol} / \mathrm{L})$, which is the diagnostic threshold for familial hypercholesterolemia ${ }^{9}$. We noticed an even larger effect of the variant on LDL cholesterol levels, when also including individuals prescribed cholesterol-lowering drugs, especially among homozygous carriers (Table 1 and Figure 
medRxiv preprint doi: https://doi.org/10.1101/2022.01.12.22269132; this version posted January $12,2022$. The copyright holder for this preprint (which was not certified by peer review) is the author/funder, who has granted medRxiv a license to display the preprint in

It is made available under a CC-BY-NC-ND 4.0 International license .

S4). Of note, prescription of cholesterol-lowering drugs was significantly associated with higher LDL cholesterol levels, across all individuals, as well as only heterozygous or homozygous p.G137S Aallele carriers (Figure S4).

We also validated the association between p.G137S and levels of total cholesterol $(\beta, 0.71 \mathrm{mmol} / \mathrm{L}$, $\mathrm{P}=1.8 \cdot 10^{-72}$, Table 1) and apolipoprotein $\mathrm{B}\left(\beta, 0.12 \mathrm{~g} / \mathrm{L}, \mathrm{P}=1.7 \cdot 10^{-17}\right.$, Table 1). Furthermore, we observed a novel association between p.G137S and lower HDL cholesterol levels ( $\beta,-0.058 \mathrm{mmol} / \mathrm{L}$ $\mathrm{P}=0.00041$, Table 1), and an increased frequency of the use of cholesterol-lowering drugs among risk A-allele carriers (odds ratio (OR) (95\% confidence interval (CI)),1.54 (1.08-2.20), $\mathrm{P}=0.016$, Table 1). With respect to basic clinical markers of cardiovascular health, we observed nominally significantly higher levels of urinary albumin-to-creatinine ratio as well as carotid intima-media thickness (Table 1). We found no associations to phenotypes related to body composition (Table S2). Our tests were adjusted for different ancestries through a mixed model and we observed no indication of inflation of the test statistics based on P-value QQ plots for all genotyped variants in the genome (Figure S5).

\section{Variance explained by the p.G137S variant}

Given the large effect size estimates obtained for some of the lipid traits, we estimated the amount of phenotypic variance explained by the variant for these traits. Based on partial $\mathrm{R}^{2}$ from a linear model that included PCs, sex, age, and survey, the p.G137S variant explained $11.8 \%$ of the variance for LDL cholesterol. Restricting the analyses to 696 individuals with more than 95\% Inuit ancestry, the variance explained increased to $16.8 \%$ (Figure S6B). We also compared the impact of the variant to that of the main known clinical risk factors for elevated LDL cholesterol, namely BMI, sex, smoking, age, and waist-hip ratio. We found that the p.G137S variant explained more variance of LDL cholesterol than any of these risk factors both when including all risk factors in the model and when estimating partial $\mathrm{R}^{2}$ from a model, which only included a single risk factor and the PCs (Figure 2A). To enable comparisons with other variants, we also estimated the variance explained using a less flexible, but commonly used approach based on summary statistics ${ }^{28}$. This led to similar, but slightly lower estimates of $10.4 \%$ variance explained in all individuals and $14.9 \%$ in individuals with more 
medRxiv preprint doi: https://doi.org/10.1101/2022.01.12.22269132; this version posted January $12,2022$. The copyright holder for this preprint (which was not certified by peer review) is the author/funder, who has granted medRxiv a license to display the preprint in

It is made available under a CC-BY-NC-ND 4.0 International license .

than $95 \%$ Inuit ancestry only (Figure S6A). Compared to the p.G137S variant, the variants identified in a recent large European GWAS ${ }^{29}$ had much lower effect sizes and explained much less of the observed variance in LDL cholesterol levels (Figure 2B and 2C).

\section{Analyses of NMR-based lipoprotein profile and metabolic phenotypes}

To explore the effect of the p.G137S variant further, we tested for associations with NMR based measurements of lipoprotein particles and metabolic markers in up to 1520 Greenlanders from our separate Greenlandic cohort. We found a similar effect on overall lipid levels as in the main Greenlandic cohort (Figure S7), however, we also found that variant carriers had a significantly smaller diameter of LDL particles $\left(\beta_{\mathrm{SD}}(\mathrm{SE}),-0.22(0.05), \mathrm{P}=1.7 \cdot 10^{-6}\right)$, and higher concentrations of all three subclasses of LDL particles (Large, 0.64 (0.04), P=2.6• 10-48; Medium, 0.63 (0.04), $\mathrm{P}=1.8 \cdot 10^{-46} ;$ Small, $\left.0.62(0.04), \mathrm{P}=1.6 \cdot 10^{-45}\right)$, IDL particles (0.62 (0.04), $\left.\mathrm{P}=4.7 \cdot 10^{-45}\right)$, and the smallest subclasses of VLDL particles (Small, $0.18(0.05), 1.6 \cdot 10^{-4}$; Very small, $0.49(0.04)$, $\mathrm{P}=6.6 \cdot 10^{-29}$; Figure 3). In these particles, the content of total lipids, phospholipids, cholesterol, cholesterol esters, free cholesterol, and triglycerides, were all significantly higher in p.G137S carriers (Figure S7). In line with the higher levels of LDL cholesterol, the p.G137S carriers also had higher levels of Apolipoprotein B (0.50 (0.04), 2.9・10-29; Figure 3). Moreover, p.G137S was significantly associated with higher concentration of several cholesterol subtypes, and with a pattern of HDL particles, with significantly higher concentrations of $\mathrm{HDL}_{3}$ cholesterol $\left(0.20(0.05), \mathrm{P}=1.3 \cdot 10^{-5}\right)$, but significantly lower concentrations of large and medium HDL particles (Large, -0.18 (0.05), $\mathrm{P}=1.3 \cdot 10^{-4}$; Medium, $-0.28(0.05), \mathrm{P}=5.7 \cdot 10^{-9}$; Figure 3). With respect to phospholipids and glycerides, the p.G137S carriers had significantly higher concentrations of total phosphoglycerides (0.19 (0.05), $\left.\mathrm{P}=3.0 \cdot 10^{-5}\right)$, phosphatidylcholine and other cholines $\left(0.19(0.05), \mathrm{P}=3.8 \cdot 10^{-5}\right)$, sphingomyelins (0.45 (0.04), $\left.\mathrm{P}=5.7 \cdot 10^{-24}\right)$, and total cholines $\left(0.26(0.04), \mathrm{P}=4.7 \cdot 10^{-9}\right.$; Figure 3$)$, and affected some classes of fatty acids. We observed no effect on the concentration of amino acids, or markers of glucose metabolism (Figure S8). 
medRxiv preprint doi: https://doi.org/10.1101/2022.01.12.22269132; this version posted January $12,2022$. The copyright holder for this preprint (which was not certified by peer review) is the author/funder, who has granted medRxiv a license to display the preprint in

It is made available under a CC-BY-NC-ND 4.0 International license

\section{Analysis of cardiovascular disease outcomes}

We also analysed if the p.G137S variant had an effect on CVD outcomes in a data set comprising the 4565 individuals, for whom we had both genetic and CVD data.

For the p.G137S carriers we observed a significantly higher risk of ischemic heart disease (HR $(95 \%$ CI), 1.51 (1.18-1.92), $\mathrm{P}=0.00096)$, peripheral artery disease (1.69 (1.01-2.82), $\mathrm{P}=0.046)$, and coronary operations (1.78 (1.21-2.62), $\mathrm{P}=0.0035$; Figure 4 and Table S3). For these three types of CVD outcomes, heterozygous and homozygous carriers had lower survival rates as a function of years lived compared to non-carriers (Figure 4, Table S3, Figure S9 and S10). A QQ plot of the test statistics from testing all genotyped variants in the genome showed no indications of inflation of the test statistics in the Cox regression analyses (Figure S11). We observed similar HRs when assessing years since inclusion, instead of years lived (Table S4), and when analysing CVD risk cross-sectionally (Table S5). Remarkably, the observed effect of the p.G137S variant on ischemic heart disease, when doing a cross-sectional analysis in Greenlanders was much greater than the effect of any common variant identified in Europeans ${ }^{30}$ (Figure 2D). Moreover, these associations remained when adjusting for BMI, smoking, and blood pressure (data not shown). On the contrary, we observed no association with cerebrovascular disease, or a combined measure of the different types of CVD events (Figure 4 \& Table S3).

\section{Investigating through which phenotype the effect on CVD is mediated}

Since the p.G137S variant is strongly associated with higher levels of LDL cholesterol, total cholesterol, apolipoprotein B, and lower levels of HDL cholesterol, the effect on CVD risk could be mediated by one of these phenotypes. To investigate if this was the case, we repeated the survival analyses for each of the relevant CVD outcomes with these four lipid phenotypes as covariates one at a time. For ischemic heart disease and peripheral artery disease these analyses showed that the association of the p.G137S variant was still statistically significant after adjusting for HDL cholesterol, and total cholesterol, respectively. However, it was not statistically significant when adjusting for LDL cholesterol for ischemic heart disease and when adjusting for apolipoprotein B for peripheral artery disease (Table S6). 
medRxiv preprint doi: https://doi.org/10.1101/2022.01.12.22269132; this version posted January $12,2022$. The copyright holder for this preprint (which was not certified by peer review) is the author/funder, who has granted medRxiv a license to display the preprint in

It is made available under a CC-BY-NC-ND 4.0 International license .

\section{Discussion}

In this study, we investigated the impact of the common Arctic specific LDLR p.G137S missense variant on specific lipids as well as metabolic and cardiovascular health in the Greenlandic population.

First, we replicated the previously reported associations with elevated circulating concentrations of LDL cholesterol, total cholesterol, and apolipoprotein B. Notably, our results showed that the p.G137S variant had an even larger impact on the lipid profile of Greenlanders than previously reported ${ }^{18}$. For LDL cholesterol, we estimated an effect size of $0.75 \mathrm{mmol} / \mathrm{L}$ per $\mathrm{p} . \mathrm{G} 137 \mathrm{~S}$ allele, whereas the previously reported estimate was $0.54 \mathrm{mmol} / \mathrm{L}^{18}$. Furthermore, we found an association with HDL cholesterol not previously reported. A likely explanation for these differences is that the previous analyses were performed using a multivariate linear model adjusting only for age, sex, BMI, and geographic location, whereas we used a linear mixed model accounting additionally for population structure and relatedness. In the admixed Greenlandic population this model enabled a more accurate estimation of effect sizes.

Interestingly, the effect size for LDL cholesterol was much larger than the effect sizes reported for any common variant identified in Europeans ${ }^{29}$. This, combined with the fact that the variant is common and carried by $29.5 \%$ of the Greenlandic population, means that the variant has a large impact on this population. This large impact on the population level, was particularly evident by the fact that $25.4 \%$ of the heterozygous and $54.7 \%$ of the homozygous carriers had LDL cholesterol levels above the diagnostic level for FH and by the fact that the explained variance for LDL cholesterol in Greenlanders was estimated to be around $12 \%$, and more than $16 \%$ when only looking at unadmixed Inuit. This estimated amount of variance explained by the $L D L R$ p.G137S variant is more than that of any identified common variant in Europeans, and also more than that of clinical risk factors like BMI, sex, smoking, age, or waist-hip ratio explain. For comparison, estimates of the amount of phenotypic variance explained by genetics in large scale European studies using polygenic risk scores range from 
medRxiv preprint doi: https://doi.org/10.1101/2022.01.12.22269132; this version posted January $12,2022$. The copyright holder for this preprint (which was not certified by peer review) is the author/funder, who has granted medRxiv a license to display the preprint in

It is made available under a CC-BY-NC-ND 4.0 International license .

$10 \%^{13}$ to $19.9 \%{ }^{31}$. Hence, the p.G137S variant alone has an impact in the Greenlandic population comparable to an entire polygenic risk score based on a large study in Europeans.

Thus, the $L D L R$ p.G137S variant is an example of a genetic variant with the unusual combination of having a large effect size and being common. This pattern is similar to the common variants with large effects on lipid levels, BMI, or risk of type 2 diabetes in isolated populations of Greeks, Greenlanders, Samoans, or Pima Indians, respectively ${ }^{32-37}$. Importantly, the $L D L R$ variant has an additive effect, and thereby potentially a bigger impact on the general population health as compared to variants with a recessive effect, like the diabetes-causing $T B C 1 D 4$ variant previously identified in Greenlanders ${ }^{35}$.

When we looked further into the effects of the p.G137S variant on the lipid-related measures, from the NMR data, we observed higher concentrations of atherosclerotic lipoproteins of LDL, IDL, and VLDL subclasses, as well as apolipoprotein B in p.G137S carriers, which is in line with reduced function of the LDL receptor. We also observed higher concentrations of $\mathrm{HDL}_{3}$ cholesterol, but lower concentrations of large and medium HDL particles, which might indicate reduced flux of cholesterol through the reverse cholesterol transport system, and thereby reduced hepatic cholesterol uptake. The observed lipoprotein profile in the carriers of the p.G137S carriers was very similar to the profile reported for children with FH with different causative mutations, however, with larger effect sizes in the children ${ }^{38}$. This difference could be due to the functional effect of the p.G137S variant, approximately reducing the ligand binding to the LDL receptor by $60 \%$, as compared to the $\mathrm{FH}$ mutations, which in general have greater functional impact ${ }^{18,39}$.

Regarding the cardiovascular disease impact of the p.G137S variant, we found a significantly increased risk of ischaemic heart disease, coronary operations, and peripheral artery disease, and observed similar effect estimates when limiting the analyses to events after inclusion or when analysing CVD risk cross-sectionally. Importantly, these findings are in line with previous results for patients with $\mathrm{FH}$, who are known to have a higher risk of CVD, especially ischemic heart disease ${ }^{9}$ but risk of cerebrovascular disease on level with the general population ${ }^{13,40}$. Generally, our findings were 
medRxiv preprint doi: https://doi.org/10.1101/2022.01.12.22269132; this version posted January $12,2022$. The copyright holder for this preprint (which was not certified by peer review) is the author/funder, who has granted medRxiv a license to display the preprint in

It is made available under a CC-BY-NC-ND 4.0 International license .

consistent with a recent Mendelian randomisation study where elevated LDL cholesterol levels were shown to be causally linked to increased risk of ischemic heart disease but not ischemic stroke ${ }^{41}$.

Apolipoprotein B has been found in a recent large Mendelian randomization study to be underlying the causal relationship of circulating blood lipids with ischemic heart disease, in a model of ischemic heart disease conditioned on apolipoprotein B and respectively LDL cholesterol and triglycerides or apolipoprotein A1 and HDL cholesterol ${ }^{42}$. For the p.G137S variant, our results failed to indicate that the level of apolipoprotein B was a better predictor of increased risk of ischemic heart disease, as the HRs were reduced similarly when adjusting for LDL cholesterol. Interestingly, the NMR analyses revealed alternative lipid species, which could be contributing to the increased risk of CVD outcomes in p.G137S carriers. Hence, in these individuals, we observed higher concentrations of both phosphatidylcholines and sphingomyelins, the latter class including ceramides. Specific subtypes of these lipid species have previously been linked to increased CVD risk, and these associations seem to be independent of other atherosclerotic risk factors, including age, BMI, smoking, triglycerides, as well as LDL and total cholesterol ${ }^{43}$. Extended lipidomics profiling assessing specific phosphatidylcholines and ceramides further elucidating these possibly causal relationships would be of great interest.

Only around $10 \%$ of the homozygous p.G137S carriers were prescribed cholesterol-lowering drugs, even though most of them had LDL cholesterol levels above $4.9 \mathrm{mmol} / \mathrm{L}$, which is the level considered diagnostic for $\mathrm{FH}^{9}$. This suggests that there are many currently untreated individuals who potentially could benefit from treatment. Moreover, we observed that the elevated levels of LDL cholesterol for p.G137S carriers was independent of age, indicating that these individuals would benefit from early intervention and treatment, similar to the recommendations for treatment of $\mathrm{FH}^{9}$. It has been shown for FH individuals that early statin therapy can help mitigate their risk of developing IHD so that it is almost similar to individuals without $\mathrm{FH}^{15,44}$. Our findings coupled with the fact that the p.G137S variant is common among Greenlanders, indicate that a screening program for the 
medRxiv preprint doi: https://doi.org/10.1101/2022.01.12.22269132; this version posted January $12,2022$. The copyright holder for this preprint (which was not certified by peer review) is the author/funder, who has granted medRxiv a license to display the preprint in It is made available under a CC-BY-NC-ND 4.0 International license .

p.G137S variant could be highly useful for early identification of individuals at increased CVD risk, hence, potentially improving preventive care and public health.

In summary, the common p.G137S variant had a major effect on the circulating lipid profile of Greenlanders, where carriers were characterised by an atherogenic lipid profile including elevated levels of LDL cholesterol, total cholesterol, and apolipoprotein B as well as an increased risk of CVD. Furthermore, the large effect size for LDL cholesterol combined with the high frequency of the variant, mean that the variant has a large population level impact. The variant is therefore a simple marker that could be used as an early indicator of future risk of increased lipid levels and CVD. Early detection of individuals likely benefiting from intervention with cholesterol-lowering drugs, could potentially lead to improved CVD prevention in Arctic populations.

\section{Acknowledgments}

We gratefully acknowledge the participants in the Greenlandic health surveys.

\section{Conflict of Interest}

The authors declare no competing interests.

\section{References}

1. World Health Organization. Global Health Estimates 2016: Disease burden by Cause, Age, Sex, by Country and by Region, 2000-2016. https://www.who.int/healthinfo/global_burden_disease/estimates/en/index1.html (2018).

2. Andersen, M. K. \& Hansen, T. Genetics of metabolic traits in Greenlanders: lessons from an isolated population. J. Intern. Med. 284, 464-477 (2018). 
medRxiv preprint doi: https://doi.org/10.1101/2022.01.12.22269132; this version posted January $12,2022$. The copyright holder for this preprint (which was not certified by peer review) is the author/funder, who has granted medRxiv a license to display the preprint in

It is made available under a CC-BY-NC-ND 4.0 International license .

3. Tvermosegaard, M., Dahl-Petersen, I. K., Nielsen, N. O., Bjerregaard, P. \& Jørgensen, M. E. Cardiovascular Disease Susceptibility and Resistance in Circumpolar Inuit Populations. Can. J. Cardiol. 31, 1116-1123 (2015).

4. Risk of fatal coronary heart disease in familial hypercholesterolaemia. Scientific Steering Committee on behalf of the Simon Broome Register Group. BMJ 303, 893-896 (1991).

5. Versmissen, J. et al. Efficacy of statins in familial hypercholesterolaemia: a long term cohort study. BMJ 337, a2423 (2008).

6. Elis, A., Zhou, R. \& Stein, E. A. Effect of lipid-lowering treatment on natural history of heterozygous familial hypercholesterolemia in past three decades. Am. J. Cardiol. 108, 223-226 (2011).

7. Raal, F. J. Lomitapide for homozygous familial hypercholesterolaemia. The Lancet vol. 381 7-8 (2013).

8. Sharifi, M., Futema, M., Nair, D. \& Humphries, S. E. Genetic Architecture of Familial Hypercholesterolaemia. Curr. Cardiol. Rep. 19, 44 (2017).

9. Youngblom, E., Pariani, M. \& Knowles, J. W. Familial Hypercholesterolemia. in GeneReviews® (eds. Adam, M. P. et al.) (University of Washington, Seattle, 2014).

10. Mundal, L. et al. Mortality among patients with familial hypercholesterolemia: a registry-based study in Norway, 1992-2010. J. Am. Heart Assoc. 3, e001236 (2014).

11. Krogh, H. W., Mundal, L., Holven, K. B. \& Retterstøl, K. Patients with familial hypercholesterolaemia are characterized by presence of cardiovascular disease at the time of death. Eur. Heart J. 37, 1398-1405 (2016).

12. Trinder, M. et al. Risk of Premature Atherosclerotic Disease in Patients With Monogenic Versus Polygenic Familial Hypercholesterolemia. J. Am. Coll. Cardiol. 74, 512-522 (2019).

13. Trinder, M., Francis, G. A. \& Brunham, L. R. Association of Monogenic vs Polygenic Hypercholesterolemia With Risk of Atherosclerotic Cardiovascular Disease. JAMA Cardiol (2020) doi:10.1001/jamacardio.2019.5954.

14. Wiegman, A. et al. Familial hypercholesterolaemia in children and adolescents: gaining decades of life by optimizing detection and treatment. Eur. Heart J. 36, 2425-2437 (2015). 
medRxiv preprint doi: https://doi.org/10.1101/2022.01.12.22269132; this version posted January $12,2022$. The copyright holder for this preprint (which was not certified by peer review) is the author/funder, who has granted medRxiv a license to display the preprint in It is made available under a CC-BY-NC-ND 4.0 International license .

15. Vuorio, A., Docherty, K. F., Humphries, S. E., Kuoppala, J. \& Kovanen, P. T. Statin treatment of children with familial hypercholesterolemia--trying to balance incomplete evidence of long-term safety and clinical accountability: are we approaching a consensus? Atherosclerosis 226, 315$320(2013)$.

16. Brown, M. S. \& Goldstein, J. L. Familial hypercholesterolemia: defective binding of lipoproteins to cultured fibroblasts associated with impaired regulation of 3-hydroxy-3-methylglutaryl coenzyme A reductase activity. Proc. Natl. Acad. Sci. U. S. A. 71, 788-792 (1974).

17. Thormaehlen, A. S. et al. Systematic cell-based phenotyping of missense alleles empowers rare variant association studies: a case for LDLR and myocardial infarction. PLoS Genet. 11, e1004855 (2015).

18. Dubé, J. B. et al. Common low-density lipoprotein receptor p.G116S variant has a large effect on plasma low-density lipoprotein cholesterol in circumpolar inuit populations. Circ. Cardiovasc. Genet. 8, 100-105 (2015).

19. Bjerregaard, P. Inuit Health in Transition: Greenland Survey 2005-2010: Population Sample and Survey Methods. (Statens Institut for Folkesundhed, 2011).

20. Bjerregaard, P. et al. Inuit health in Greenland: a population survey of life style and disease in Greenland and among Inuit living in Denmark. Int. J. Circumpolar Health 62 Suppl 1, 3-79 (2003).

21. Skotte, L. et al. Missense Mutation Associated With Fatty Acid Metabolism and Reduced Height in Greenlanders. Circ. Cardiovasc. Genet. 10, (2017).

22. Voight, B. F. et al. The metabochip, a custom genotyping array for genetic studies of metabolic, cardiovascular, and anthropometric traits. PLoS Genet. 8, e1002793 (2012).

23. Andersen, M. K. et al. Identification of Novel Genetic Determinants of Erythrocyte Membrane Fatty Acid Composition among Greenlanders. PLoS Genet. 12, e1006119 (2016).

24. Moltke, I. et al. Uncovering the genetic history of the present-day Greenlandic population. Am. J. Hum. Genet. 96, 54-69 (2015).

25. Zhou, X. \& Stephens, M. Genome-wide efficient mixed-model analysis for association studies. Nat. Genet. 44, 821-824 (2012). 
medRxiv preprint doi: https://doi.org/10.1101/2022.01.12.22269132; this version posted January $12,2022$. The copyright holder for this preprint (which was not certified by peer review) is the author/funder, who has granted medRxiv a license to display the preprint in

It is made available under a CC-BY-NC-ND 4.0 International license .

26. Chen, H. et al. Control for Population Structure and Relatedness for Binary Traits in Genetic Association Studies via Logistic Mixed Models. Am. J. Hum. Genet. 98, 653-666 (2016).

27. Therneau, T. M. \& Grambsch, P. M. Modeling Survival Data: Extending the Cox Model. (Springer, New York, NY, 2000).

28. Shim, H. et al. A multivariate genome-wide association analysis of 10 LDL subfractions, and their response to statin treatment, in 1868 Caucasians. PLoS One 10, e0120758 (2015).

29. Liu, D. J. et al. Exome-wide association study of plasma lipids in $>300,000$ individuals. Nat. Genet. 49, 1758-1766 (2017).

30. van der Harst, P. \& Verweij, N. Identification of 64 Novel Genetic Loci Provides an Expanded View on the Genetic Architecture of Coronary Artery Disease. Circ. Res. 122, 433-443 (2018).

31. Surakka, I. et al. The impact of low-frequency and rare variants on lipid levels. Nat. Genet. 47, 589-597 (2015).

32. Southam, L. et al. Whole genome sequencing and imputation in isolated populations identify genetic associations with medically-relevant complex traits. Nat. Commun. 8, 15606 (2017).

33. Andersen, M. K. et al. The derived allele of a novel intergenic variant at chromosome 11 associates with lower body mass index and a favorable metabolic phenotype in Greenlanders. PLoS Genet. 16, e1008544 (2020).

34. Grarup, N. et al. Loss-of-function variants in ADCY3 increase risk of obesity and type 2 diabetes. Nat. Genet. 50, 172-174 (2018).

35. Moltke, I. et al. A common Greenlandic TBC1D4 variant confers muscle insulin resistance and type 2 diabetes. Nature 512, 190-193 (2014).

36. Minster, R. L. et al. A thrifty variant in CREBRF strongly influences body mass index in Samoans. Nat. Genet. 48, 1049-1054 (2016).

37. Baier, L. J. et al. ABCC8 R1420H Loss-of-Function Variant in a Southwest American Indian Community: Association With Increased Birth Weight and Doubled Risk of Type 2 Diabetes. Diabetes 64, 4322-4332 (2015).

38. Christensen, J. J. et al. Comprehensive lipid and metabolite profiling of children with and without familial hypercholesterolemia: A cross-sectional study. Atherosclerosis 266, 48-57 
medRxiv preprint doi: https://doi.org/10.1101/2022.01.12.22269132; this version posted January 12,2022 . The copyright holder for this preprint (which was not certified by peer review) is the author/funder, who has granted medRxiv a license to display the preprint in It is made available under a CC-BY-NC-ND 4.0 International license .

(2017).

39. Hobbs, H. H., Russell, D. W., Brown, M. S. \& Goldstein, J. L. The LDL receptor locus in familial hypercholesterolemia: mutational analysis of a membrane protein. Annu. Rev. Genet. 24, 133-170 (1990).

40. Huxley, R. R. et al. Risk of fatal stroke in patients with treated familial hypercholesterolemia: a prospective registry study. Stroke $\mathbf{3 4}, 22-25$ (2003).

41. Valdes-Marquez, E. et al. Relative effects of LDL-C on ischemic stroke and coronary disease: A Mendelian randomization study. Neurology 92, e1176-e1187 (2019).

42. Richardson, T. G. et al. Apolipoprotein B underlies the causal relationship of circulating blood lipids with coronary heart disease. Cardiovascular Medicine (2019) doi:10.1101/19004895.

43. Ding, M. \& Rexrode, K. M. A Review of Lipidomics of Cardiovascular Disease Highlights the Importance of Isolating Lipoproteins. Metabolites 10, (2020).

44. Nordestgaard, B. G. et al. Familial hypercholesterolaemia is underdiagnosed and undertreated in the general population: guidance for clinicians to prevent coronary heart disease: consensus statement of the European Atherosclerosis Society. Eur. Heart J. 34, 3478-90a (2013).

45. II. Rationale for Intervention. Circulation 106, 3163-3223 (2002). 


\section{Figure legends}
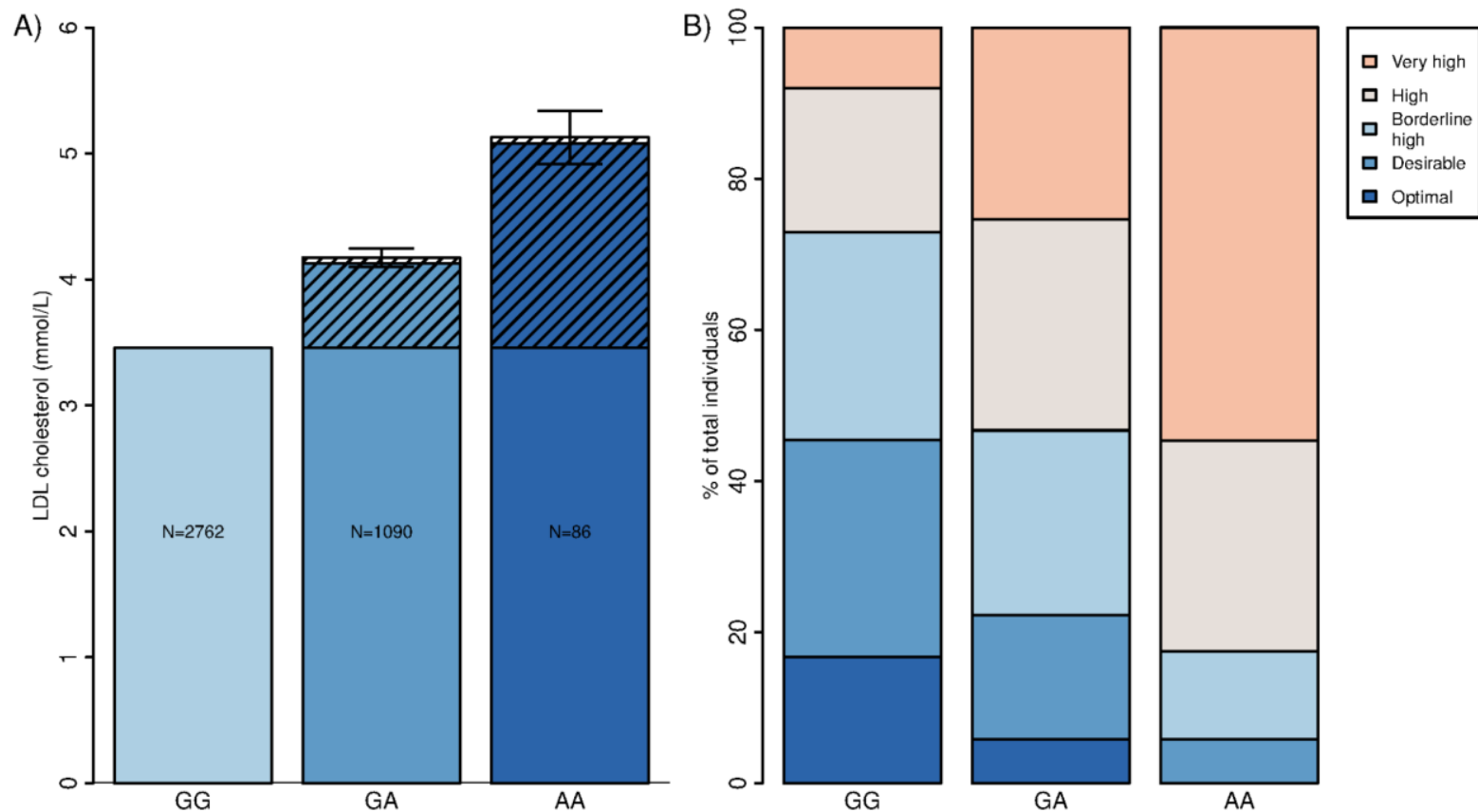

Figure 1. Effect of p.G137S variant on circulating lipid levels. A) Mean levels of LDL cholesterol stratified per genotype, as well as estimated effect sizes from GEMMA according to a full model (hatched area) with $95 \%$ confidence intervals. The number of participants in each group is written inside the bars. B) For each genotype group the proportion of different LDL cholesterol level categories are shown. The LDL cholesterol level categories are according to US guidelines ${ }^{45}$ with < $2.6 \mathrm{mmol} / \mathrm{L}$ being Optimal, 2.6-3.3 mmol/L being Desirable, 3.4- $4.0 \mathrm{mmol} / \mathrm{L}$ being Borderline high, 4.1- $4.8 \mathrm{mmol} / \mathrm{L}$ being High and $\geq 4.9 \mathrm{mmol} / \mathrm{L}$ being Very high. 

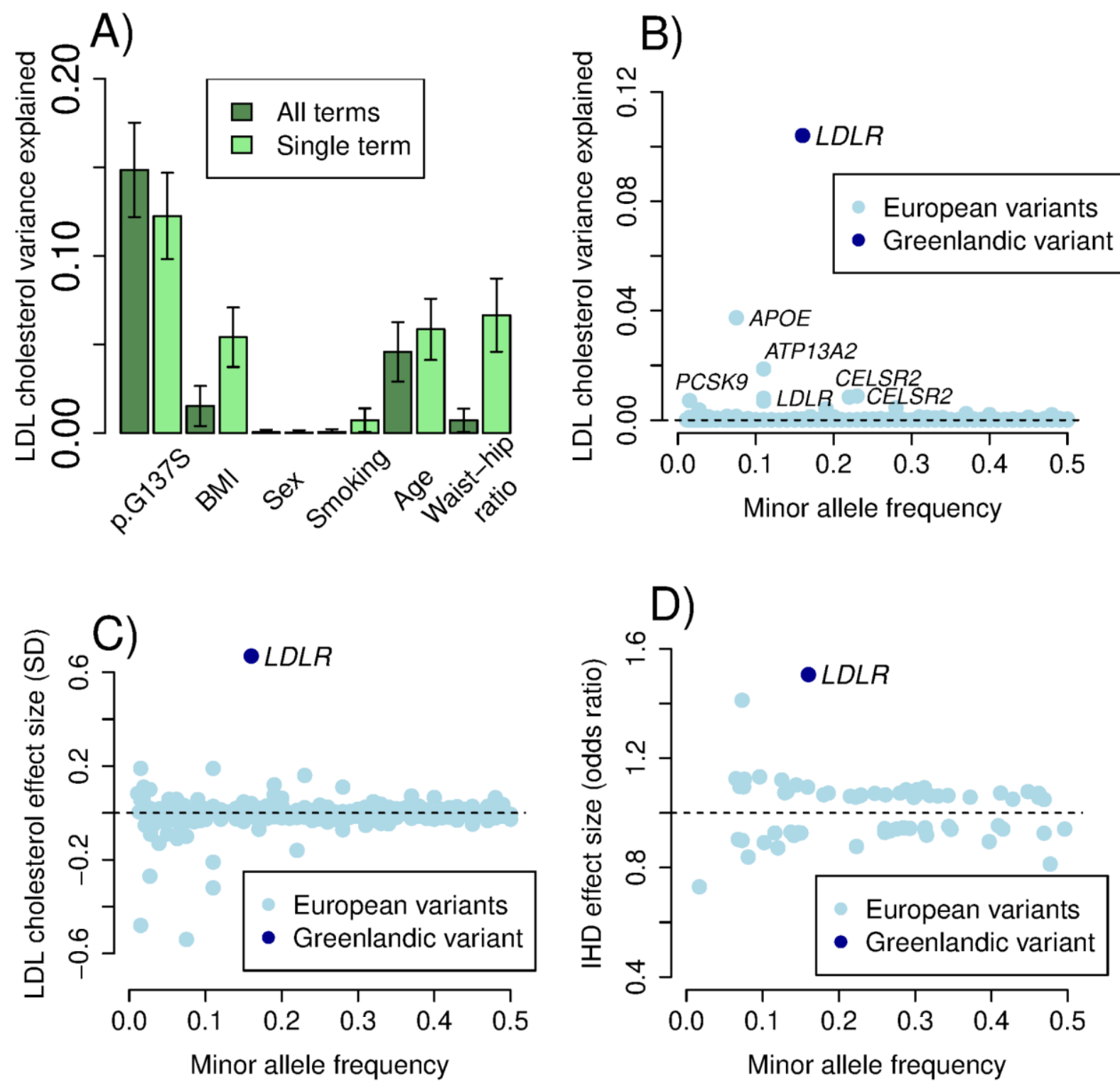

Figure 2. Effect sizes and explained variance of common variants associated with LDL cholesterol and ischemic heart disease in Europeans and the $L D L R$ p.G137S variant in

Greenlanders. A) Comparison of LDL cholesterol variance explained by the p.G137S variant, BMI, sex, smoking, age, and waist-hip ratio, respectively in a model including all terms (All terms) as well as a model including the terms one at a time (Single term), B) estimated LDL cholesterol variance (using quantile transformed effect sizes) explained by $L D L R$ p.G137S in Greenlanders, and the genetic variants identified to be associated with LDL cholesterol levels in Europeans ${ }^{29}$ (with gene names), C) LDL cholesterol effect sizes for $L D L R$ p.G137S in Greenlanders, and the genetic variants 
medRxiv preprint doi: https://doi.org/10.1101/2022.01.12.22269132; this version posted January $12,2022$. The copyright holder for this preprint (which was not certified by peer review) is the author/funder, who has granted medRxiv a license to display the preprint in

It is made available under a CC-BY-NC-ND 4.0 International license.

identified to be associated with LDL cholesterol levels in Europeans ${ }^{29}$, and $\left.\mathbf{D}\right)$ the odds ratio for ischemic heart disease for $L D L R$ p.G137S variant in Greenlanders, and genetic variants identified to be associated with increased risk of ischemic heart disease in Europeans ${ }^{30}$. Genetic variants with a minor allele frequency $<0.01$, have been omitted from the plot.
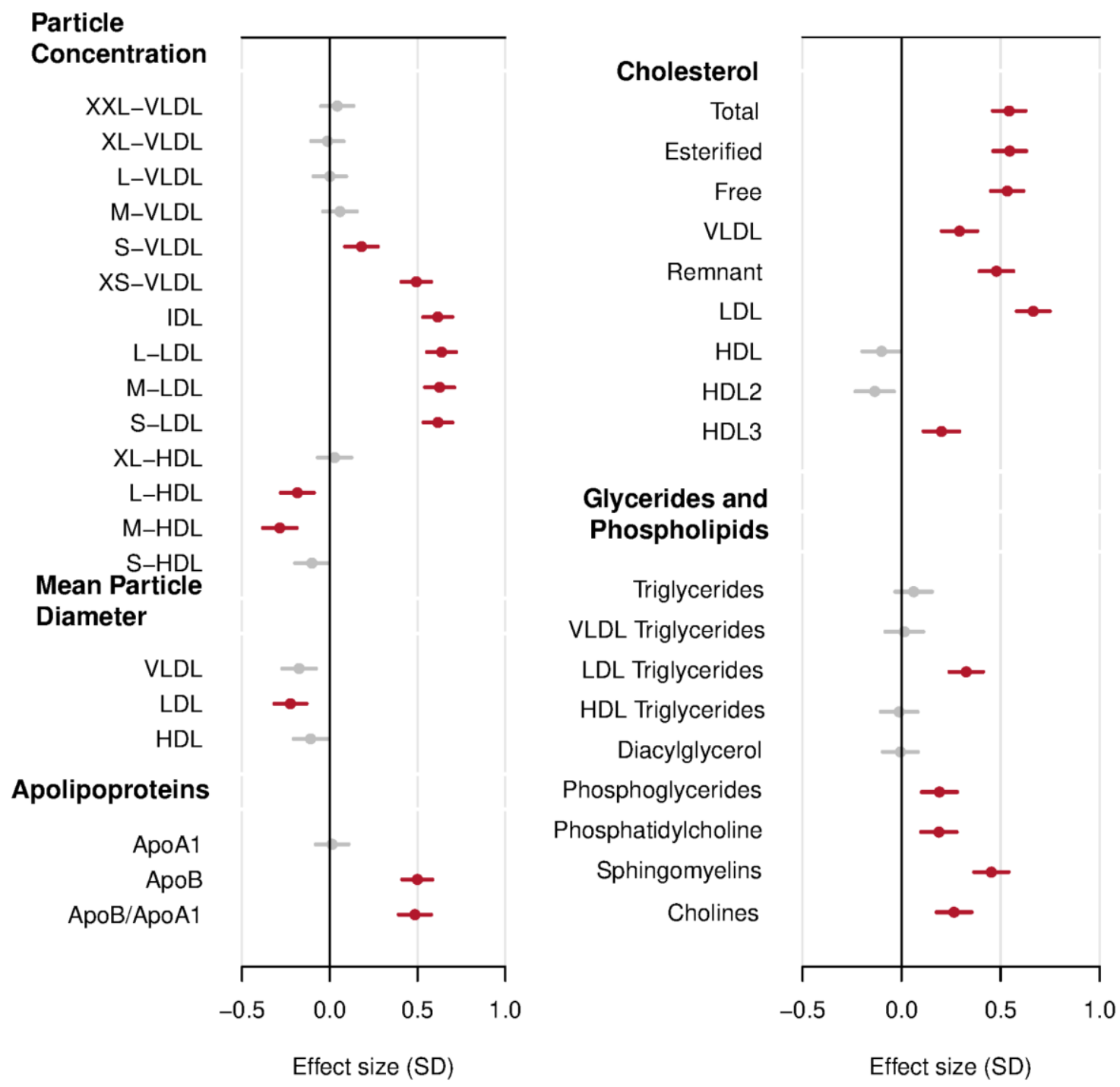

Figure 3. Effect of the p.G137S variant on concentration of lipoprotein particles and cholesterol

species. Lipoprotein particle concentration and metabolic measures in Greenlanders with NMR phenotypes. Estimates of the effect size of the p.G137S variant are shown with their 95\% confidence interval, furthermore the confidence intervals are coloured red if their P-value is below the bonferroni correction of $3.3 \cdot 10^{-4}$, and grey otherwise. Phenotype values were quantile transformed to a standard 
medRxiv preprint doi: https://doi.org/10.1101/2022.01.12.22269132; this version posted January 12,2022 . The copyright holder for this preprint (which was not certified by peer review) is the author/funder, who has granted medRxiv a license to display the preprint in It is made available under a CC-BY-NC-ND 4.0 International license

normal distribution. XXL, extremely large; XL, very large; L, large; M, medium; S, small; XS, very small; VLDL, very low-density lipoprotein; IDL, intermediate-density lipoprotein; LDL, low-density lipoprotein; HDL, high-density lipoprotein; Apo, apolipoprotein. 


\section{The p.G137S variant associated with CVD outcomes}

\section{Any CVD event \\ (627 events)}

Ischemic heart disease

(237 events)

Cerebrovascular disease

(362 events)

Peripheral artery disease

(47 events)

Heart failure

(161 events)

Coronary operations

(88 events)

$(N=4565)$

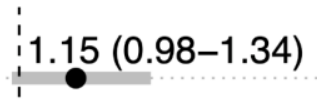

$P-$ value $=0.085$

$1.51(1.18-1.92)$

$P-$ value $=0.001$

$P-$ value $=0.507$

$P$-value $=0.046$

$P-$ value $=0.684$

$1.69(1.01-2.82)$

$1.07(0.78-1.46)$

$1.78(1.21-2.62)$

$P-$ value $=0.003$

Hazard Ratio + $95 \%$ Confidence Intervals

Figure 4. Estimated hazard ratios for the p.G137S variant on CVD. Hazard ratios are shown with their 95\% confidence interval and $\mathrm{P}$-values $(\mathrm{P})$ estimated with Cox regression testing for an association between the p.G137S variant and risk of different types of CVD events. The red colour denotes those where the P-value is below the bonferroni correction of 0.00833 . 


\section{Tables}

Table 1. Analyses of association between the p.G137S variant and circulating lipids and cardiovascular health markers

\begin{tabular}{|l|l|l|l|l|}
\hline Trait & $\mathrm{n}$ & $\beta_{\mathrm{SD}}(\mathrm{SE})$ & $\beta$ & $\mathrm{P}$ \\
\hline Lipid profile & & & & \\
\hline Fs LDL cholesterol (mmol/L) & 3938 & $0.67(0.031)$ & 0.75 & $5.5 \cdot 10^{-87}$ \\
\hline Fs LDL cholesterol (mmol/L)* & 4077 & $0.67(0.031)$ & 0.79 & $1.7 \cdot 10^{-90}$ \\
\hline Fs total cholesterol (mmol/L) & 4496 & $0.56(0.029)$ & 0.69 & $1.8 \cdot 10^{-72}$ \\
\hline Fs total cholesterol (mmol/L)* & 4636 & $0.56(0.029)$ & 0.71 & $2.5 \cdot 10^{-75}$ \\
\hline Fs HDL cholesterol (mmol/L) & 4631 & $-0.11(0.030)$ & -0.058 & 0.00041 \\
\hline Fs triglyceride (mmol/L) & 4105 & $0.043(0.033)$ & 0.025 & 0.19 \\
\hline Apolipoprotein B (g/L) & 1232 & $0.51(0.057)$ & 0.12 & $1.7 \cdot 10^{-17}$ \\
\hline Apolipoprotein A1 (g/L) & 1232 & $-0.13(0.058)$ & -0.034 & 0.032 \\
\hline Fs VLDL cholesterol (mmol/L) & 2086 & $-0.043(0.045)$ & -0.0091 & 0.34 \\
\hline Remnant cholesterol (mmol/L) & 3938 & $0.034(0.034)$ & 0.0055 & 0.31 \\
\hline Cholesterol-lowering drugs^ & 2870 & 1.54 OR (0.18) & - & 0.016 \\
\hline Cardiovascular profile & 1524 & $0.0023(0.050)$ & 0.12 & 0.96 \\
\hline Pulse rate (beats per minute) & 4133 & $-0.014(0.030)$ & -0.12 & 0.65 \\
\hline Systolic blood pressure (mmHg) & 4133 & $-0.056(0.031)$ & -0.61 & 0.072 \\
\hline $\begin{array}{l}\text { Diastolic blood pressure } \\
\text { (mmHg) }\end{array}$ & 1063 & $0.080(0.039)$ & 0.013 & 0.042 \\
\hline Albumin-to-creatinine ratio in & 2560 & $0.076(0.037)$ & 7.9 & 0.042 \\
\hline urine (mg/L) & & & & \\
\hline Garotid intima-media thickness & $4 \mathrm{~m})$ & & \\
\hline
\end{tabular}

$*=$ including individuals taking cholesterol-lowering drugs.

$\wedge$ = binary trait.

Each analysis was both run with the phenotype quantile transformed to a standard normal distribution for each sex $\left(\beta_{\mathrm{SD}}\right)$ and without any transformation $(\beta)$. The P-values are from the transformed analyses. $\beta$, effect size; SD, standard deviation; SE, standard error. 
medRxiv preprint doi: https://doi.org/10.1101/2022.01.12.22269132; this version posted January 12, 2022. The copyright holder for this preprint (which was not certified by peer review) is the author/funder, who has granted medRxiv a license to display the preprint in It is made available under a CC-BY-NC-ND 4.0 International license 

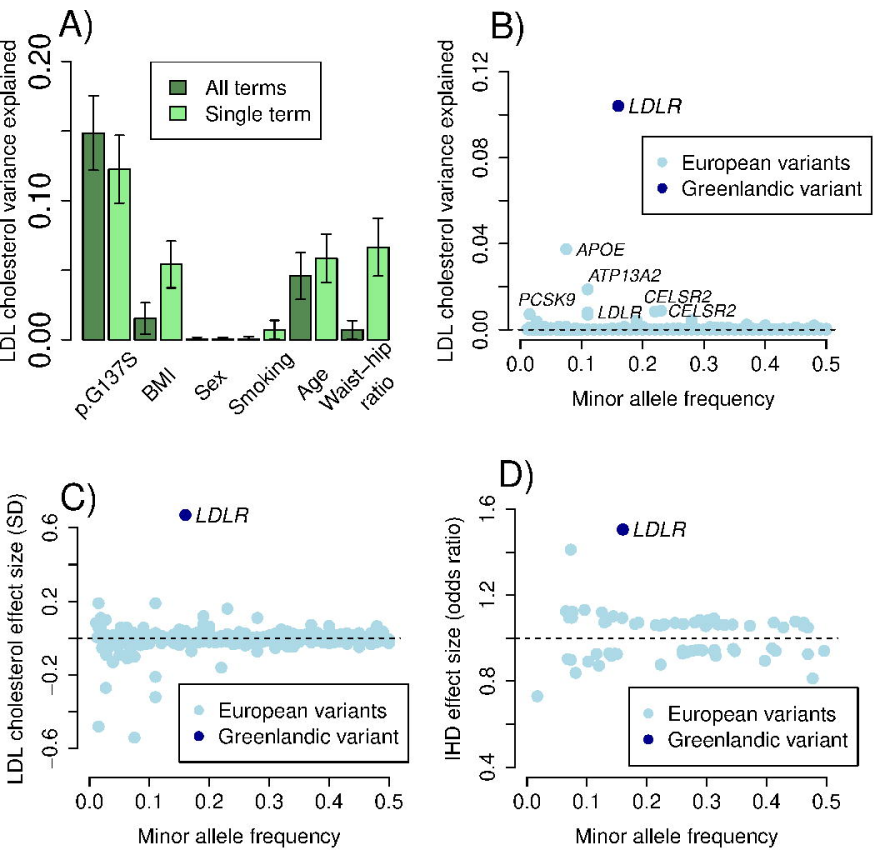

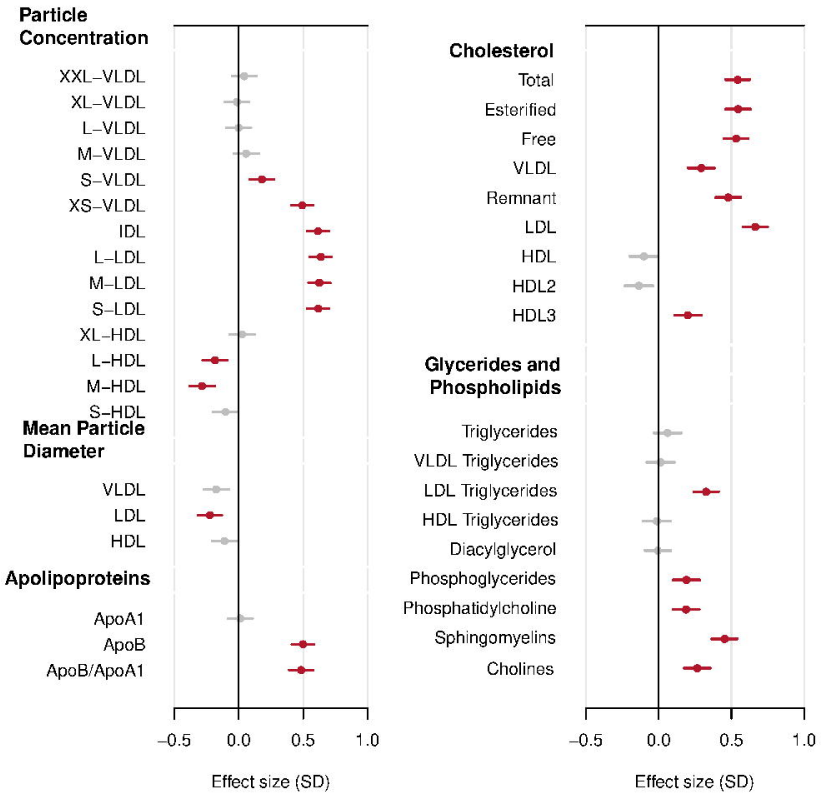


\section{The p.G137S variant associated with CVD outcomes}

Any CVD event (627 events)

Ischemic heart disease

(237 events)

Cerebrovascular disease

(362 events)

Peripheral artery disease

(47 events)

Heart failure (161 events)

Coronary operations

(88 events)
$1.15(0.98-1.34)$

$1.51(1.18-1.92)$

$1.07(0.87-1.32)$

$1.69(1.01-2.82)$

$1.07(0.78-1.46)$

$1.78(1.21-2.62)$

$P-$ value $=0.046$

$P-$ value $=0.684$

$P-$ value $=0.003$

$P$-value $=0.507$

$(N=4565)_{0.7} \quad 1 \quad 32$

Hazard Ratio + $95 \%$ Confidence Intervals 